This item was submitted to Loughborough's Research Repository by the author.

Items in Figshare are protected by copyright, with all rights reserved, unless otherwise indicated.

\title{
Embodied social capital and geographic perspectives: performing the habitus
}

PLEASE CITE THE PUBLISHED VERSION

http://dx.doi.org/10.1177/0309132507087648

PUBLISHER

(c) SAGE Publications

VERSION

AM (Accepted Manuscript)

LICENCE

CC BY-NC-ND 4.0

REPOSITORY RECORD

Holt, Louise. 2019. "Embodied Social Capital and Geographic Perspectives: Performing the Habitus". figshare. https://hdl.handle.net/2134/13089. 
This item was submitted to Loughborough's Institutional Repository (https://dspace.lboro.ac.uk/) by the author and is made available under the following Creative Commons Licence conditions.

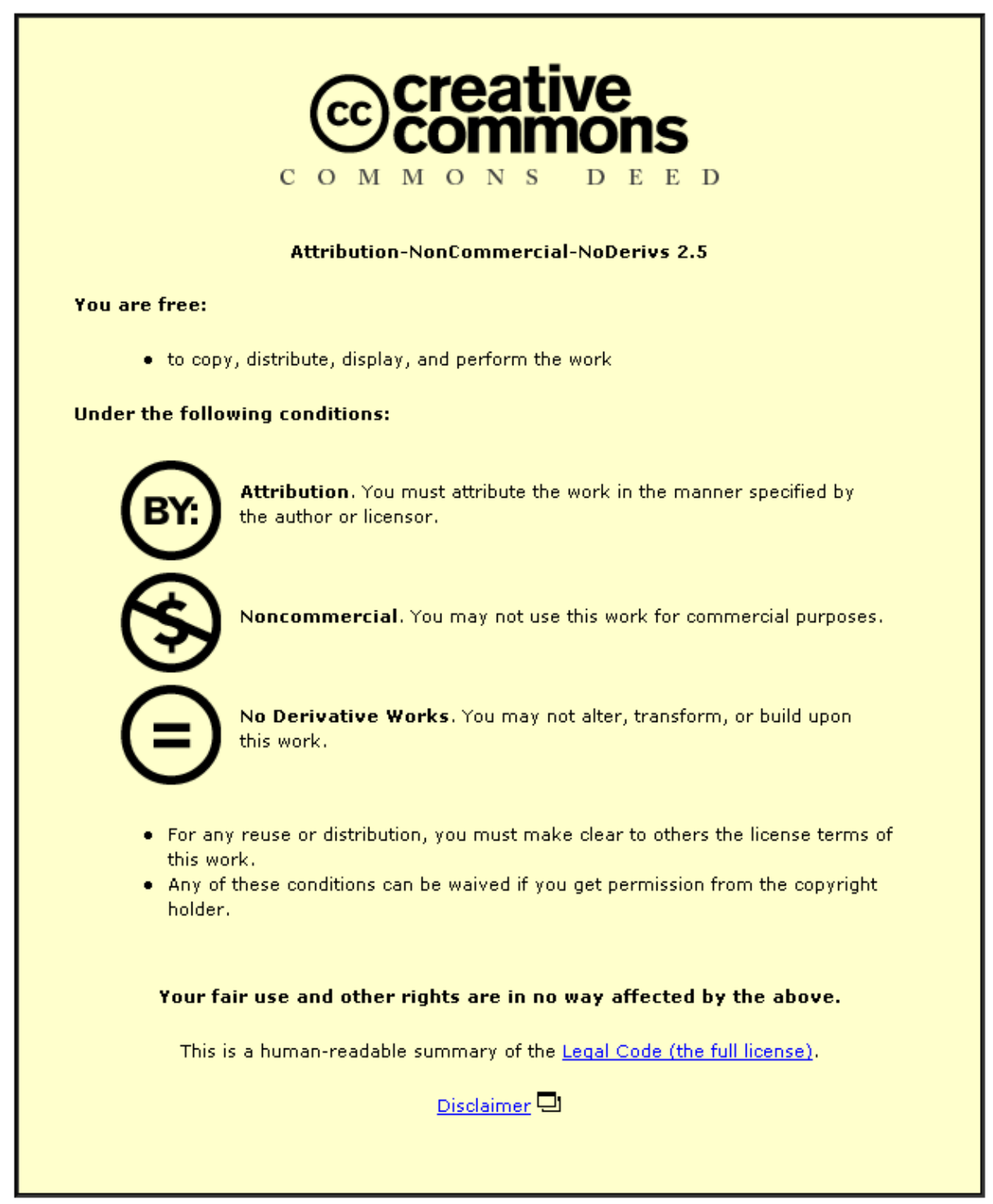

For the full text of this licence, please go to: http://creativecommons.org/licenses/by-nc-nd/2.5/ 
Forthcoming Progress in Human Geography

\section{Embodied social capital and geographic perspectives:}

performing the habitus

Louise Holt

Department of Geography

University of Reading

Whiteknights, PO Box 227

Reading,

RG6 6AB,

UK

01183788733 


\title{
Embodied social capital and geographic perspectives:
}

\section{performing the habitus}

\begin{abstract}
This paper re-opens debates of geographic theorizations and conceptualizations of social capital. I argue that human geographers have tended to underplay the analytic value of social capital, by equating the concept with dominant policy interpretations. It is contended that geographers could more explicitly contribute to pervasive critical social science accounts. With this in mind, an embodied perspective of social capital is constructed. This synthesizes Bourdieu's capitals and performative theorizations of identity, to progresses the concept of social capital in four key ways. First, this theorization more fully reconnects embodied differences to broader socio-economic processes. Second, an exploration of how embodied social differences can emerge directly from the political-economy and/or via broader operations of power is facilitated. Third, a path is charted through the endurance of embodied inequalities and the potential for social transformation. Finally, embodied social capital can advance social science conceptualizations of the spatiality of social capital, by illuminating the importance of broader socio-spatial contexts and relations to the embodiment of social capital within individuals.
\end{abstract}

\section{Key words}

Embodied, social capital, performativity, normalization, reproduction, transformation, exclusion, inclusion, Bourdieu, Butler 


\section{A I Introduction}

Recent commentaries have illuminated how the utilization of social capital within human geography is on the wane, with some authors suggesting that geographical accounts of social capital are '(almost) dead' (Radcliffe, 2004: 517). However, a vibrant research agenda which focuses upon social capital continues to flourish within broader social science investigations (e.g. Families and Social Capital ESRC Research Centre, London South Bank University). Taking inspiration from this fertile research terrain, this paper seeks to reinvigorate debates of the analytic value of social capital for human geographers, by more fully opening the 'black box' of social capital (Radcliffe 2004: 519). The rationale for this is twofold. First, human geographers may be in danger of missing the opportunity of recapturing a concept which continues to have high political currency at a variety of intersecting institutional levels, from the global (e.g. World Bank) to the micro (Amin, 2005; Mohan et al., 2005). At a UK national scale, social capital and related concerns (such as community capacity and civic relations) are integral to New Labour's 'Third Way'i approach (Baron, 2004). Social capital features prominently in a variety of UK national policy arenas, particularly health (Health Development Agency, 2004), community development, and social exclusion and inclusion (Social Exclusion Unit, 2004). Second, I contend that critical concepts of social capital can have analytical value. It is therefore useful for geographers to contribute to debates of social capital.

Broadly, social capital illuminates the value of social relationships and networks to societies and individuals. However, it is a highly contested concept (DeFilippis, 2001). There is much divergence between the three key 'theorists' of social capital; 
Robert Putnam, James Coleman, and Pierre Bourdieu (Schaefer-McDaniel, 2004). Robert Putnam's envisionings of social capital have been particularly influential within policy accounts. It can be argued that many geographical debates of social capital have focused upon the dominant conceptualization forwarded by Putnam (Putnam et al, 1993; Putnam, 2000). Consequently, the diversity of approaches to social capital has been somewhat under represented within geography (cf. DeFilippis, 2001). Given fundamental criticisms levelled at Putnam (e.g. Portes, 1998), it is not surprising that many geographers have 'disinvested" (Foley and B.Edwards, 1999) in social capital.

I argue that this disinvestment is problematic as social capital can have potential analytical value, although it requires explicit conceptualization. In particular, critical accounts of social capital can provide insights into the (re)production of inequalities and advantage through everyday sociability within a variety of intersecting social networks. It is therefore valuable to challenge and endeavour to resignify dominant representations of social capital.

As an alternative to dominant accounts, this paper provides a reconceptualization of social capital, which focuses upon how social capital becomes embodied within individuals' dynamic corporeality. Embodied social capital engages with Bourdieu's theories of capitals, which been influential within the broader social sciences (e.g. Morrow, 2001; Adkins, 2004; Reay, 2004a). I argue that Pierre Bourdieu's accounts address many of the critiques levelled at social capital by geographers (e.g. Mohan and Mohan, 2002; Das, 2005). Three key aspects of Bourdieu's conceptualization of social capital are of particular importance to this discussion. First, Bourdieu 
emphasizes the inter-relations between social capital and a variety of capitals, including cultural and economic. Second, Bourdieu highlights how the social is one key form of capital that serves to (re)produce socio-economic differentiation and inter-generational (dis)advantage, rather than operating as a 'general social good' (cf. Putnam, 2000). Third, although not fully developed in relation to social capital, Bourdieu offers a nuanced and embodied account of agency via the concepts of practice and habitus. Habitus provides an insight into the embodied and pre-reflexive, albeit always socio-spatially contextualized, nature of practice. In this paper, I synthesize Bourdieu's insights into social capital and habitus with Judith Butler's conceptualization of performativity and subjection to point to an embodied conceptualization of social capital.

The paper is divided into four key sections. In the following section, I review some geographical accounts of social capital. The subsequent section engages with critical social science debates to discuss Bourdieu's conceptualization of social capital. I then outline the concept of embodied social capital, which synthesizes Bourdieu's capitals with Butler's performativity and subjection theories. In the 'Discussion' section I briefly consider how embodied social capital can be empirically mobilized. Finally, a brief conclusion is offered.

\section{A II Geographical accounts of social capital}

The concept of social capital occupies a contradictory position within human geography and the policy arena. It has high political currency within a range of national and 'global' political bodies (e.g. Health Development Agency, 2004; Social 
Exclusion Unit, 2004; The World Bank - Bebbington et al., 2004). By contrast, many human geographers, following endeavours to operationalize social capital, have decried the concept as having only limited, if any, explanatory value (DeFilippis, 2001; Radcliffe, 2004; Das, 2004; Mohan et al., 2005 ${ }^{\text {iii }}$ ). Indeed, the 'decline' of social capital is increasing taken as a given within geographical debates (Houston et al. 2005).

Overall, these geographical contributions are critical of social capital as articulated within health-related (Mohan et al., 2005) or development fields (DeFilippis, 2001; Amin, 2005; Radcliffe, 2004). Arguably, this scepticism is tied to the capture of social capital by dominant policy perspectives, which are limited and even erroneous. Policy understandings of are predominantly associated with Robert Putnam's ${ }^{\text {iv }}$ envisionings of social capital, and/or endeavours to synthesize ontologically and epistemologically disparate conceptualizations. The political ascendancy of particular versions of social capital tends to underplay the conceptual weaknesses that social scientists have identified as (almost) fatal flaws within Putnam's accounts (DeFilippis, 2002).

Arguably, the apparently contradictory positions of social capital within policy arenas and human geography debates are interconnected. Although geographers, in common with many social scientists, are highly sceptical of the neo-liberal ${ }^{\mathrm{v}}$ underpinnings and apparent 'panacea' (Fine, 2001) status of dominant representations of social capital (Amin, 2005; Mohan and Mohan, 2002), these facets are attractive to many policymakers, given the generalized neo-liberal shift in global and national governance. As Ponthieux (2004: 19) states, social capital: 
‘... may have appeared as a miracle remedy to solve deep social problems, and ease the experts' charitable minds, particularly since it is apparently costless (...not requiring higher taxes)'.

Dominant accounts of social capital have been subject to criticism upon interconnected conceptual, methodological and epistemological grounds (Amin, 2005; Foley and B.Edwards, 1999; Jackman and Miller, 1998; Portes and Landolt, 1996). Despite these critiques, facets of Putnam's accounts have proved enduring. Putnam's conceptualization of the nature and formation of social capital holds particular appeal. Social capital has been equated to membership of formal civic organizations (Putnam 2000). Sub-themes of informal social relationships and generalized norms of trustingness, trustworthiness and reciprocity are also evident. The general consensus that social capital is constructed through formal, and to a lesser extent, informal social networks has been widely adopted, even within critical accounts (e.g. Li et al, 2002, 2003a, 2003b; Mohan et al., 2005). Formal networks within voluntary associations are often prioritized. Many studies utilize quantitative measures not specifically designed to measure social capital. Increasingly, however, specific 'social capital' variables are incorporated into large-scale surveys, such as the UK General Household Survey (GHS) and national censuses (ONS, 2002).

In addition to existing critiques, I contend that Putnam's accounts demonstrate troubling ontological tendencies, as he endeavours to produce an objectivist and even universal account (Grootaert, 1998; cf. Bebbington et al., 2004). Indeed, Putnam (2000: 228) claims that: 'an impressive and growing body of research suggests that civic connections help make us healthy, wealthy and wise'. The causal, universally 
applicable status accorded to social capital in Putnam's theorizations are implicitly bound-up with a particular neo-liberal politics that shifts the cause of inequality, hardship, socio-economic exclusion and poverty away from the operations of the political economy ultimately onto individuals' and groups' civic engagement (Fine, 2001).

Such universalizing tendencies may be particularly unappealing to geographers on a variety of grounds; not least due to a lack of a critical conceptualization of space. Putnam treats spaces as static, pre-existing, and 'given'. Such an approach contrasts with complex conceptualizations of space and spatiality forwarded by geographers and other social scientists (e.g. Massey, 2005). Mohan et al. (2005) illuminate some practical limitations of Putnam's view of space. More explicitly, however, dominant conceptualizations of social capital do not fully consider places as 'becoming'; as dynamic material expressions of broader socio-spatial processes and power enactments, which then constrain and enable social change.

Overall, geographers have critiqued dominant envisionings of social capital, rather than fully re-theorizing the concept in critical dialogue with social science accounts. Mohan and Mohan (2002) in this journal are ambivalent towards hegemonic versions of social capital. However, rather than fully destabilizing Putnam's version of social capital, they critically engage with, and aim to enhance, his measures. Unsurprisingly, then, when empirically mobilizing their conceptualizations of social capital, Mohan et al. (2005: 1282) conclude: 
'...we suggest that our work adds weight to a growing body of research ... which challenges the explanatory power of social capital (vis-à-vis material circumstances) and which is therefore sceptical about whether demonstrable health benefits will be obtained from investing in social capital'.

By contrast, DeFilippis (2001) begins to re-signify social capital, to transform hegemonic understandings. By drawing upon Bourdieu (especially 1986) and Loury (1977), DeFilippis points to the need to theorize how social networks can reproduce unequal relations of capital in a socio-economic sense, and power in more general terms. Thus, DeFilippis enhances geographical debates of social capital. However, his account does not fully take on board critical socio-cultural conceptualizations of power and community. Thus, power is viewed as something tangible which can be held, or transferred, rather than as multifarious and having diverse expressions, including operating through embodied individuals (cf. G.Rose, 1997). Although DeFilippis critiques Putnam's suggestions that communities have 'agency', he does not fully question whether communities can be representative of the individuals that comprise them (cf. Amin, 2005). The ways in which dominant and marginalized identity positionings, and a variety of inclusions and exclusions, can be (re)produced within community groups and associations, requires further exploration.

Critiques, which have illuminated such points, have often emerged from feminist perspectives, highlighting gender as an axis of difference (e.g. Silvey and Elmhurst, 2003). At the same time, these discussions have generally not offered a new conceptualization of social capital that more substantially illuminates gendered differences, and have tended to jettison Bourdieu's accounts, by contrast to feminist 
research within other disciplines (Skeggs and Adkins, 2004; Reay, 2004a; Silva, 2005). Although focusing attention upon the norms reproduced though sociability, feminist discussions have not as yet fully married social capital theory with understandings of normalization power. Further, most accounts of social capital in geography have underplayed other social differences, and how they intertwine with those of gender and 'social class'. Radcliffe (2004: 527) states:

\begin{abstract}
'Social capital's specific approach to social interaction has tended to focus attention away from analyses of social difference, primarily aspects of gender and ethnicity (issues around disability, generation and sexuality are completely off the radar as yet)'.
\end{abstract}

In the rest of the paper I critically engage with Bourdieu's theory of social capital to forward the concept of embodied social capital. Embodied social capital simultaneously engages with, and suspends, interpretations that emerge from Bourdieu, which have received attention within social sciences, and considers broader issues of power, identity and inequality.

\title{
A III Retheorizing social capital as a mechanism for reproducing privilege
}

Bourdieu's conceptualization of social capital addresses many of the critiques levelled at Putnam; including the lack of sensitivity to socio-economic inequalities and wider historical-political and material processes. Further, Bourdieu does not posit social capital as an independent variable. By contrast, he theorizes the co-construction of a variety of 'capitals' (social, cultural, symbolic and economic) through which privilege 
Forthcoming Progress in Human Geography

and disadvantage are covertly reproduced (T.Butler and Robson, 2001). Thus, a reconfigured conceptualization that draws upon Bourdieu's social capital can address the scathing critique of social capital by Das (2004: 27):

'...it is untenable to posit social capital as an independent variable and poverty as a dependent variable because the economic-political conditions of poor people have an enormous constraining effect on social capital itself and its supposed material benefits for the poor'.

\section{B. 1 Defining (social) capital}

Bourdieu $(1984,1986)$ conceives of social capital as one of four key forms of capital, along with economic, cultural (embodied, objectified or institutional), and symbolic (Painter, 2001; T.Butler and Robson, 2001; Gatrell et al., 2004). Social capital is defined as:

'... the aggregate of the actual or potential resources which are linked to possession of a durable network of more or less institutionalized relationships of mutual acquaintance and recognition - or in other words, to membership in a group - which provides each of its members with the backing of the collectively-owned capital, a 'credential' which entitles them to credit, in the various senses of the word' (Bourdieu, 1986: 249-250).

Importantly, Bourdieu offers insights into both the measurement and the (re)production of social capital. It is theoretically possible to measure an individual's social capital, given: 
'The volume of the social capital possessed by a given agent ... depends on the size of the network of connections he [sic] can effectively mobilize and on the volume of the capital (economic, cultural or symbolic) possessed in his [sic] own right by each of those to whom he [sic] is connected' (Bourdieu, 1986: 250).

This theoretical measurement of social capital is arguably difficult to mobilize empirically (Baron, 2004; cf. Gatrell et al., 2004; Silva and R.Edwards, 2004). Such an understanding of social capital is certainly not currently measurable via the largescale quantitative data sets favoured by many advocates of social capital.

The key significance of Bourdieu's work is the emphasis placed on the differing capital value of social relationships. Individuals who have access to particular social networks will be able to mobilize this social capital, transforming it into different types of capital; maintaining their advantages within particular 'fields' of activity ${ }^{\mathrm{vi}}$. Bourdieu emphasizes that social capital requires an investment:

'...the network of relationships is the product of investment strategies, individual or collective, consciously or unconsciously aimed at establishing or reproducing social relationships that are directly usable in the short or long term i.e. at transforming contingent relations ... into relationships that are at once necessary and elective, implying durable obligations selectively felt (feelings of gratitude, respect, friendship) or institutionally guaranteed (rights)' (Bourdieu, 1986: 250-251). 
More attention could be paid to the hierarchical and conflictual nature of all social relationships (Turner and An Nguyen, 2005). It is unlikely that all members of any given social network have equal access to the capital resources held by all other members. However, Bourdieu does nuance his argument to suggest that investments made into social capital, like those in cultural capital, do not guarantee a particular 'return'. Investing in social capital is a risky venture; given a member of the network may fail to perceive or act upon a mutual obligation. As the transformation of the social into capital depends upon an unspoken, intuitive agreement, unfulfilled obligations must be commonplace. It therefore seems reasonable to question the value of investing in social (or cultural) capital. Bourdieu suggests that the benefits of cultural and social capital are as concealed forms of intergenerational capital accumulation, which reproduce privilege and disadvantage, and thus defy attempts at redistribution, such as progressive taxation. His work on cultural capital (Bourdieu, 1984; Bourdieu and Passeron, 1979) illuminates more fully how these processes of capital accumulation are concealed within the taken-for-granted assumptions of meritocracy and democracy.

There is evidently a recursive relationship between the development of social and cultural capital. Cultural capital (institutionalized, objectified, and perhaps most importantly embodied) facilitates the development of social capital. For instance, particular forms of institutional and objectified cultural capital may open up spaces within which particular contingent relationships can emerge (such as the golf-club or the university). Further, embodied cultural capital inculcates within individuals the dispositions and manners which facilitate the types of appropriate sociability which 
Forthcoming Progress in Human Geography

allow the 'alchemy of consecration' (Bourdieu, 1986: 251) to transform contingent relationships into relations of mutual obligation.

Conversely, social capital can facilitate the acquisition of cultural capital. For instance, the social networks to which an individual belongs influences the individual, embodied habitus (Bourdieu and Thompson, 1991). Equally, at a more obvious level, the social networks to which children and young people belong encourage or constrain their acquisition of institutionalized cultural capital, in the form of educational qualifications (W.Thomas and Webber, 2001). Thus, the interconnections between social and cultural capital are far more complex and nuanced than suggested by Coleman (1988).

\section{B 2. A more nuanced understanding of agency}

Along with theorizing the co-construction of capitals, Bourdieu offers a more nuanced understanding of the subject/agent, via habitus, which emphasizes the beyond conscious, habitual, embodied and non-reflexive elements of practice. The intersection between habitus and the accumulation of social capital is clearly fruitful for a consideration of embodied social capital. However, to date, within geographical accounts, discussion of habitus and social capital remain largely disparate. By contrast, habitus has been theorized within studies of cultural capital, most notably within the fields of gentrification (e.g. T.Butler 1997; T.Butler with Robson, 2003; Bridge, 2001; Ley, 2003, Podmore, 1998; D.Smith and Phillips, 2001; Zukin, 1995), and migration (Kelly and Lusis, 2006). Recent accounts have interpolated the fields of education with gentrification (T.Butler and Robson 2003b; Bridge, 2006) and migration (Walters, 2006). The concept of habitus has been refined and empirically 
investigated via studies of the 'metropolitan or inner city (gentrification) habitus' (T.Butler, 2002; Ley, 2003), 'rural habitus' (D.Smith and Phillips, 2001) 'minihabituses; (Bridge, 2006) and the 'transnational habitus' (Kelly and Lusis, 2006).

Habitus is the embodied materialisation of individuals' capitals, or 'internalized capital' (Bourdieu, 1984: 114; Painter, 2001; Shilling, 2003). Habitus is expressed via embodied dispositions, largely subconsciously inculcated, primarily, although not exclusively, during childhood (Bourdieu and Thompson, 1991). Jenkins (1992) identifies three key ways in which 'dispositions' are utilized within Bourdieu's conceptualization of habitus: first as an organising principal for engaging in practice habitus provides an unconscious framework and resource drawn upon in individuals' encounters with the world; second, as a 'way of being' or 'habitual state' (including deportment and ways of speaking); and third as 'tendency', 'propensity' or 'inclination' - tastes (p. 76) (see also Reay, 2004b). These three elements of habitus are clearly interconnected, and thus habitus provides an unconscious backdrop to individuals' practices within particular social 'fields' ${ }^{\text {vii }}$. Jenkins (1992: 76) states that:

'The habitus disposes actors to do certain things; it provides a basis for the generation of practices. Practices are produced in and by the encounter between the habitus and its dispositions, on the one hand, and the constraints, demands and opportunities of the social field or market to which the habitus is appropriate or within which the actor is moving, on the other' 
One of Bourdieu's central concerns is to overcome key dichotomies within the social sciences; notably between 'structure' and 'agency' and 'objectivity' and 'subjectivity'. Thus, although habitus prioritizes experience and everyday practice, it is not from a position that accords epistemological privilege to the individual who experiences (McNay, 2004). Bourdieu endeavours to negotiate a path between the all knowledgeable (humanist) actor and individuals as 'epiphenomena' of structures (Bouveresse, 1999) by establishing habitus as a context to social action which, although dynamic, exhibits a certain friction to change. Habitus is the mechanism by which the 'objective' external world, expressed as 'fields' becomes incorporated within the 'subjective' internal, embodied, experience. It is, 'those embodied rituals of everydayness by which a given culture produces and sustains belief in its own "obviousness" (J.Butler, 1999: 114). Thus, dominant relations in society are often reproduced via habitus, as frequently social and cultural relations are not reflected upon, they are just 'lived' (Cresswell, 1996).

Rather than being consciously learned, habitus is acquired via less-than-conscious embodied practices, or 'mimesis'; the subconscious inculcation of the specific 'rules of the game' of a particular field (Bourdieu, 1990: 66). Habitus then provides a 'practical knowledge' or 'feel for the game' which is drawn upon when negotiating unfamiliar social contexts or fields (Bourdieu and Wacquant, 1992). Thus, habitus mediates the positions that individuals occupy in new social fields. Habitus is therefore a key mechanism for the reproduction of intergenerational inequality (Bourdieu and Passeron, 1979), given its production in relation to the position held within the fields that an individual has previously encountered, particularly during childhood (Bourdieu and Thompson, 1991). 
Thus, Bourdieu's conceptualization of habitus questions other key dichotomies in social science, including that between mind/body, conscious/unconscious (Lawler, 2004) and body/society (Shilling, 2003), by illuminating how practice is simultaneously a series of conscious and beyond conscious embodied acts which are socially situated. This decentring of body-individual and society facilitates a variety of interpretations of habitus as variously primarily embodied within individuals (e.g. R.Nash, 2003) or as a collective, shared consciousness, which can ultimately be mapped onto tangible spaces (e.g. T.Butler and Robson, 2001; D.Smith and Phillips, 2001). Bourdieu's habitus also resonates strongly with enduring concerns about the beyond consciousness, the reflexive and the Affectual realm within human geography (Cresswell, 2002; Probyn, 2004). However, by contrast to recent geographical concerns with the Affectual, which often prioritizes flexibility above endurance (Holt, forthcoming), Bourdieu's concept of habitus is a particularly useful lens for examining social reproduction. As Cresswell (2002: 381) contends '...the habitus represents the internalisation of the social order, which in turn reproduces the social order'.

The notion of habitus facilitates a more nuanced understanding of agency within social capital. Bourdieu emphasizes that agents are only partially knowledgeable; they are also influenced by subconscious and embodied motivations. Therefore, it is not necessary for an individual to be consciously aware of the value of their social relationships for these networks to count as capital (cf. Morrow, 1999). Equally, sociability that confers social capital is not (always) consciously engaged in for personal gain (cf. Coleman, 1988). For Bourdieu, capital exchanges may be sub- 
Forthcoming Progress in Human Geography

conscious and governed by dispositions and choices that defy rational reflection. The key strength of Bourdieu's 'capitals', is that they bring to light concealed intergenerational processes that serve to reproduce socio-economic advantage, disadvantage and privilege.

\section{B. 3. Critiques of Bourdieu's capitals habitus}

Bourdieu's theories of capitals, habitus and practice are not without limitations. Three critiques are particularly focused upon here. First, Bourdieu often prioritizes social reproduction above transformation. Second, although usefully emphasizing the role of the broader political economy to the (re)production of social capital, Bourdieu's account arguably veers into economic reductionism by placing the political-economy at the root of all capitals. This has implications for Bourdieu's theories of agency and the applicability of his accounts for theorizing differences other than class and class faction. Finally, Bourdieu's accounts are not particularly sensitive to spatial differences. I suggest that these critiques can begin to be resolved by synthesizing Bourdieu's theory of capitals with performative understandings of power and identity developed by Judith Butler.

First, although Bourdieu explicitly endeavoured to move away from structuralism, his focus on the reproduction of privilege and inequality serves to foreground reproduction rather than instances of transformation (Jenkins, 1992). Thus, albeit agency is important to Bourdieu's theorizations, many analyses influenced by his work underplay the potential for individuals to act as agents to transform general structural patterns (e.g. R.Nash, 2003). Thereby, the duality of 'structure' and 
'agency' is somewhat under-theorized in Bourdieu's analyses. Bridge (2001) argues that Bourdieu underplays the role of purposeful agency. By uniting Bourdieu and 'game theory', a subset of Rational Action Theory, Bridge (2001) usefully destabilizes the epistemological privilege accorded by Bourdieu to the researcher. Unlike the majority of individuals, Bourdieu represents social scientists as capable of, and responsible for, instigating change in the objective relations of the field (Bourdieu and Wacquant, 1992). However, Bridge's approach is also in danger of sidelining some of the key contributions of habitus, notably the role of embodied, intuitive, extra-reflexive dispositions to practice, and habitus as an embodied historic consolidation of pervious social relationships. Although action can be, if not rational, then purposeful and reflexive, destabilising the erroneous rational and autonomous agent is crucial to attempts to illuminate the subconscious and pre-reflexive level at which much social reproduction occurs.

Second, despite Bourdieu's attempts to overcome the economic reductionism inherent in historical-materialist accounts, his capitals ultimately refer back to socio-economic advantages and disadvantages emanating from the capitalist mode of production and consumption (Jenkins, 1992). Thus, despite illuminating the need to examine the 'specific efficacy of the other [non-economic] types of capital' Bourdieu (1986: 253), he insists that this efficacy occurs precisely due to "the fact that economic capital is at their root, in other words - but only at the last analysis - at the root of their effects' (ibid.). This insistence on the sovereignty of the economic ultimately casts children and other groups rendered dependent, and therefore unable to convert other forms of capital into economic gain, as somehow outside of capitals. This tendency is problematic for social scientists interested in examining children's social capital 
(Morrow, 1999). A further consequence of this apparent economic reductionism is that, although Bourdieu's influential notion of habitus is embodied, linking bodily dispositions to socio-economic and cultural factors (Shilling, 2003), there are difficulties inherent in applying habitus to embodied (dis)advantages that do not exclusively emerge from the capitalist political economy and class (faction) relations, such as gender (Silvey and Elmhurst, 2003; Reay, 2004a), 'race' or 'ethnicity', and disability (cf. C.Edwards and Imrie, 2003; C.Allen, 2004), despite some explicit attempts by Bourdieu to engage with gender differences (Bourdieu, 2001; Dillabough, 2005; Silva, 2005).

This tendency to focus upon the class or class faction habitus is reproduced within geographical debates (see for instance T.Butler and Robson, 2001; T.Butler, 2002; Ley, 2003; Walters, 2006). Therefore, the host of embodied inequalities reproduced, and potentially transformed, through everyday practice, have not been fully illuminated within geographic discussions of Bourdieu's capitals. By contrast, recent debates are beginning to consider the importance of a variety of social differences to the acquirement of social capital (e.g. Nederveen Pieterse, 2006). Radcliffe (2006: 24) points to the need to further synthesize the role of a host of social differences and embodied power relations to conceptualizations of social capital:

'The conversation initiated by social capital would be usefully directed towards the analysis of class, gender, and racial-ethnic relations that underpin social networks and forms of inequality. The challenge is to maintain this conversation around culturally meaningful interactions embedded in complex articulations of politics, power, race, and global-local ties'. 
Finally, and connected to Radcliffe's call for a spatially sensitive approach to social capital, although geographers have usefully enhanced Bourdieu's rather dualistic theorizations of objective and social space (e.g. T.Butler and Robson, 2001; D.Smith and Phillips, 2001), Bourdieu's most influential theories and empirical work have tended to underplay the difference that space/place makes (for exception see Bourdieu, 1990; Painter, 2001; McNay, 2004). Schaefer-McDaniel (2004) begins to consider the importance of material spaces and places to young people's 'social capital'. She develops a conceptualization of social capital of resonance to children and youth, which has three key components: 'social networks and sociability', 'trust and reciprocity' and 'sense of belonging and place attachment'. The third of these elements provides a useful starting point for conceptualizing social capital and space/place. Within Schaefer-McDaniel's account, these spaces are presented as preexisting the performances that bring them to life. A useful way forward would be to consider Bourdieu's capitals in light of performative understandings of place/space (Gregson and G.Rose, 2000). Thus, geographers could more fully tease out how social capital is embodied through individuals' encounters in particular 'places' which are specific, unbounded, moments in broader socio-spatial relationships (Massey, 2005). Hence geographers could increasingly explore the socio-spatially specific (re)production, and perhaps also the transformation, of broader-scale (in)equalities through individual embodiments.

Bourdieu's notion of social capital is useful for illuminating the role of sociability and social networks in reproducing socio-economic inequality. Thus, such a vision of social capital begins to answer calls to re-emphasize a particular type of material, and 
Forthcoming Progress in Human Geography

enduring 'structural' inequalities and privileges, within human geography and accounts of social capital. Inequality and equality are, however, not exclusively linked to social 'class' or 'class factions'. Thus, it is necessary to bring into play some wider operations of power. Power is a diffuse subject matter which is inherently difficult to define (cf. J.Allen, 2003); not least because many of its operations are insidious. Social relationships and the powers they constitute, reproduce and transform are multi-layered and multifaceted. In the following section, I focus on Judith Butler's performativity theories and her (Foucauldian) notion of subjectification in order to explicitly theorize the reproduction and transformation of embodied inequalities.

\section{A IV Embodying social capital}

There are keen points of commonality between Judith Butler's performativity and Bourdieu's habitus and capitals, engendering some debate between the two theorists (see McNay, 2004). For instance, Butler (1999) critiques Bourdieu's rather static and dualistic conceptualizations of 'habitus' and 'fields'. Despite acknowledging Bourdieu's attempts to overcome the dominant dualism between the objective and subjective, Butler contends that this dichotomy is reinscribed within the division between the 'subjective' (habitus) versus 'objective' (field). Butler suggests that this dualistic representation of habitus and field underplays the interconnection and dynamism between the field and habitus. Habitus can be altered due to 'objective' changes in the field whereas the 'field' is taken as an objective and pre-existing given. Thus Bourdieu denies individuals (other than social scientists) the capacity to alter the conditions of the field; ultimately reinscribing an agency/structure dualism (Jenkins, 1992). 
Despite the many contributions of the notion of habitus, a dualism is established between the 'internal' (subjective) body and 'external' (objective) society (Butler, 1999), which has been problematized from a variety of perspectives (Grosz, 1994; Doel, 1995; Shilling, 1997, 2003). This underplays the dynamic nature of embodiment which only becomes within specific socio-spatial encounters; and presents fields and space as static, isotropic surfaces. An engagement between feminist and post-structuralist theories of performativity and Boudieu's theories of capital, could begin to answer these critiques levelled at habitus. At the same time such a mutual dialogue could serve to more fully re-connect such theories of embodiment to enduring material inequalities and the (re)production of privilege (McNay, 2004).

By contrast to Bourdieu, feminist and/or post-modernist/post-structuralist scholars have emphasized the diversity of embodied inequalities, rather than reifying 'class' as a social cleavage. Arguably most attention has been paid to gender, sexuality, and race/ethnicity (Gregson and G.Rose, 2000; Bell et al., 1994; M.Thomas; 2005). Increasingly, geographers are illuminating age and (dis)ability as embodied sociospatial differences (Holt, 2004a, forthcoming; C.Edwards and Imrie, 2003). Importantly, these axes of identity do not operate in isolation from each other; rather they are intertwined and mutually recursive. Individuals are differentially gendered, classed, racialized, sexualized, (dis)abled, and so on (Moss and Dyck, 1996; C.Allen, 2004). Such embodied locations are key mechanisms for the (re)production of broader patterns of (dis)advantage. To take the example of (dis)ability; many individuals defined as disabled experience high levels of marginalization and exclusion within 
social, economic, cultural and political arenas (Kitchin, 1998; R.Butler and Parr, 1999; Imrie and C.Edwards, forthcoming).

Understanding embodied identities as the site of the reproduction (and potential transformation) of broader societal differences requires a destabilization of some key naturalized dichotomies. First, evidently, the dualism between the body and society is deconstructed. Thus, bodies are reconfigured as unbounded and cross-cut and dissected by broader power relations (Longhurst, 2001). Second, nature and society are reconfigured as mutually reinforcing and constituted (G.Rose, 1993). The 'nature' of the materiality of the body is not a pre-given, rather it is a dynamic material processes intersecting with, and impinging upon, social and cultural relations (Shilling, 2003). Third, the dichotomy between the self and society is critiqued; in particular the dominant conceptualization of an interior and socially anterior psyche (Foucault, 1990; J.Butler, 1997).

The performativity behind individuals' becoming as human subject/agents has been illuminated from a number of theoretical starting-points (e.g. Thrift and Dewsbury, 2000; Harrison, 2000; Dewsbury et al., 2002; Latham and Conradson, 2003). Crucially, performativity theory has highlighted that apparently natural subject positions, such as gender/sex, 'race', or 'disability' (Holt, forthcoming) are inherently fragile repetitions. Feminist theories of performativity, drawing upon Judith Butler (1990, 1993, 1997, 2000), have emphasized how norms of appropriate identity performances become unconsciously inculcated into individuals. Thus, identity performances are not entirely conscious, rationalized or staged; they are often just ‘done' (Gregson and G.Rose, 2000; C.Nash, 2000). Performativity theories illuminate 
that the agent does not precede the 'doing' of the performative act or event. Rather, the actor 'becomes' through the event, while simultaneously drawing upon and reproducing a historical consolidation of previous (gendered) acts (J.Butler, 1993) ${ }^{\text {viii }}$. The fragility of the performance or the event, which is configured by the juxtaposition of a host of human and non-human actants, raises the importance of context. The playing-out of identity is thus inherently spatial (M.Thomas, 2005). The spatial contexts of performances, however, are themselves not just 'given'; rather they are performed and 'become' through enactments of power (Gregson and G.Rose, 2001).

\section{B. 2. Negotiating reproduction and transformation}

Performative theories of identity point to the relationality and contextuality of individual subjectivity. Such theories have the potential to redress the balance away from the reproduction of 'structures' as opposed to transformation within Bourdieu's capitals, and provide a more nuanced understanding of 'structure' and 'agency'. At the same time, an engagement between performativity theory and Bourdieu's capitals can promote a sharper focus upon how the 'non-representational', 'affectual', 'emotional' realm, which is always equivocal, fragile and contextual, often (re)produces relatively enduring material socio-spatial inequalities via embodied social identities. This would address some critiques levelled at post-structuralist thought (Martin, 2001). Although these are arguably overly simplistic representations ${ }^{\mathrm{ix}}$ of the terrain, perhaps performativity/non-representational theories tend to focus upon the specific, the idiographic, the unique - the potential to be otherwise (Harrison, 2000), the fragility and the dynamism above the endurance and the (re)production of enduring social inequalities. In particular, such accounts tend to shy away from explicitly exploring how such identity performances are 
interconnected with, (re)produce, and can transform, broader scale 'patterns' of material socio-spatial inequality (see also McNay, 2004). For instance, M.Thomas (2005: 1235) following M.Rose (2002) argues 'against reading practice within a sociostructural framework'. By contrast, it is arguably important to consider how everyday performances (re)produce or transform socio-spatial expressions of inequality operating at a variety of interconnected spatial scales (Holt, forthcoming).

Understanding broader embodied identity locations, such as gender, race, sexuality, and disability as embodied social capital is a potential mechanism for usefully synthesizing Bourdieu's theories of capitals and performativity theory. This strategic label foregrounds the different 'value' accorded to various embodiments. Shilling (2003) labels such bodily capital 'physical capital' (see also C.Edwards and Imrie, 2003). Embodied social capital more explicitly emphasizes how the process of becoming an embodied individual is inherently bound up with the socio-spatial contexts within which people's lives are lived, and their social networks and relationships. What it means to be subjectified as, for instance, disabled, white, heterosexual, 'working class' and female, is socio-spatially contextual (M.Thomas, 2005). An individual's previous social encounters are embodied and influence their future social performances. The ways in which social, cultural, political, and economic networks come together around and through individuals' embodiments and subjectivities, requires further exploration.

The concept of embodied social capital thus destabilizes the benign norms presented in dominant accounts of social capital, by drawing upon theorizations of the diffuse power of normalization. Norms of identity performance are central to the processes by 
which a person is subjectified. Judith Butler, following Foucault, emphasizes that individuals becoming recognized as knowable subjects/agents is always configured within a normative frameworks of personhood (J.Butler, 1997, 2004). Crucially, then, subjectivities are inherently social. Rather than being bounded, individuals 'become' relationally. For instance, Judith Butler's recent work focuses upon the interdependence of human beings. This interdependence is both physical and emotional. First, we '...liv[e] in a world of beings who are, by definition, physically dependent upon one another, physically vulnerable to one another' (J.Butler, 2004: 22). Second, in an emotional sense, J.Butler (2004: 2) argues that: 'desire is always a desire for recognition and that it is only through the experience of recognition that any of us becomes constituted as socially viable beings'. By pointing to the emotionality of existence, Butler's discussions of recognition provide insight into why individuals (subconsciously) accept marginal identity positionings, or those which foreclose specific aspects of themselves. Such a position emphasizes that emotional interdependence is a central mechanism for the inculcation of norms that ultimately confer embodied capital, pointing to a further facet of the centrality of geographies of emotions to issues of political, social, cultural and economic (re)production (K.Anderson and S.Smith, 2001; Davidson et al., 2005).

It is through relationships based upon a measure of reciprocity and trust (and no doubt also a mix of conflict and distrust) that normative expectations of personhood are transmitted often through beyond-conscious relational bodily acts. These norms are frequently not consciously conveyed; rather they are (re)produced though practices and constellations that often confound, or at least render complex, the representational. These norms and expectations become incorporated into individuals' 
self-identity, as people recognize themselves and are recognized by others as subject/agents.

To briefly trace a substantive example, I draw upon some previous research, which examined how (dis)ability is (re)produced as an embodied identifier by children and adults though mundane everyday practices, primarily within school spaces (see Holt, 2003, 2004a, 2004b, forthcoming). Children's experiences of being cast as (dis)abled via institutionalized processes and everyday practices is socio-spatially shifting, even at relatively small spatial scales, and interconnected with other axes of power relations (Holt, 2004b). However, young people often accept the positioning as 'disabled' that is offered to them, and incorporate some negative aspects of dominant discourses of disability into their sense of self. For instance, many young people internalize a position of dependence, a key facet of dominant, individual tragedy models of disability; Kitchin, 1998, perhaps because it provides a subject position that is recognized by peers. As Ben, a boy with mind and body differences, states:

“[My friend] always comes with me at playtime 'cause he didn't have a friend, and now, whenever I'm lonely and he's there, he always comes and cares for me'” (Holt, 2004a: 225).

The 'dependent' subject position that Ben accepts is socio-spatially shifting, and in other spatial contexts he might not be portrayed as dependent. However, being cast as dependent might have enduring effects, particularly if Ben is placed in such a positioning consistently or within a variety of intersecting spatial contexts. This dependence can become incorporated into Ben's sense of self and influence the 
Forthcoming Progress in Human Geography

position that he occupies within other socio-spatial relations, both present and future. Crucially, Ben's subjectification as 'disabled' and 'dependent' interconnects with broader patterns of socio-spatial inclusion/exclusion, given the marginalized position that devalued performances of disability often (re)produce (Kitchin, 1998).

Hence, the 'norms' produced through sociability are wider than those seemingly innocuous ties of reciprocity and trust ${ }^{\mathrm{x}}$, emphasized in dominating accounts of social capital. These norms influence (but do not determine) the different levels of capitals which individuals can acquire. However, differences such as gender/sex, 'race', 'disability', age, and sexuality are as central to the unequal distribution of capitals as class and class faction.

\section{B. 3. Spatiality, transformation and embodied social capital}

The norms that (re)produce identity positions are not fixed or given; they are dynamic and subject to change (J.Butler, 2004). This opens up at least two potentialities. First, these norms are socio-spatially variable, and, importantly, intersecting (see Holloway, 1998; Duncan and D.Smith, 2002, in relation to class and gender). This focus on things coming together in specific spatial contexts provides an opening for a more spatially sensitive theory of capitals. It emphasizes that capitals are not simply inculcated in a vacuum; rather individuals' capital accumulation occurs within specific spatial moments - themselves not neutral and pre-existing, but becoming though everyday performances and within broader 'power geometries' (Massey, 1994). However, I would argue that, to date, much performativity theory has not fully articulated how individual embodied identities are specific moments within broader 
social (economic, political, 'cultural') processes that emerge from a variety of intersecting spatial scales from the individual (including dynamic bodily materiality) to the global (cf. Katz, 2004; Aitken, 2001).

The second key potentiality is for transformation. Performative conceptualizations of identity are arguably more dynamic and shifting than Bourdieu's notion of habitus, and can more fully account for change (M.Rose, 2002; Holt, forthcoming). Norms can be transformed through conscious acts, such as re-signification (J.Butler, 2004) or contestation. In addition, transformation can occur via slippage; unconscious 'inappropriate' performances which can destabilize the expectations placed on particular bodies, and at least briefly, disrupt the appearance that identity categories are natural or given (J.Butler, 1990; Gregson and G. Rose, 2000).

Overall, I contend that the potentials of social transformation opened up by performative readings of identity have not been fully empirically realized by geographers (cf. Longhurst, 2000). Returning to my previous research provides a useful entrée point to considering the potentials for transforming dominant representations of (dis)ability. Holt (forthcoming) reflects upon how young people both reproduce and transform dominant societal positionings of (dis)ability through their everyday socio-spatial practices. Examples are provided of young people, with a diversity of mind-body-emotional characteristics, resignifying the meaning of both disability and composite components of dominant representations of disability. Although these practices are often reflective acts, the challenge made to broader discourses of disability are generally not consciously entered into. Further, examples are presented of young people producing relationships of recognition wherein mind- 
body-emotional difference is either suspended or not understood within a framework of otherness (Holt, forthcoming). The positive relationships forged within one context can become embodied within individuals and influence their negotiation of future social situations (see also Valentine and Skelton, 2003).

Such transformation is rendered complex, given norms are often reproduced within the realms of the beyond consciousness. Within the empirical examples I trace, dominant facets individual tragedy models of disability are often (re)produced, rather than transformed. Thus, attention needs to be paid to how individuals' socio-spatial positionings influence their capacity to transform broader societal processes and representations (McNay, 2004); without negating the potentialities for a range of nonconforming practices, ranging from 'resilience', 'reworking' to 'resistance' (Katz, 2004). Arguably, along with examining how enduring inequalities and exclusions are reproduced, embodied social capital can present an insight into how to affect social transformation; a central concern of human geography (Thrift, 2004; Valentine, 2005).

\section{A V Discussion}

In this paper, I have argued the need to revisit the concept of social capital within human geography, and pointed to some possible ways forward. Recent critiques levelled at social capital are arguably underpinned by the ascendancy of a disputed version within policy and some academic debates. Despite the many inadequacies of dominating accounts, the notion of social capital has re-focused policy attention to the importance of social networks, sociability and 'community' within people's everyday 
lives. However, these concepts, as applied within national and global policies, are often inherently neo-liberal and serve to detract from, rather than enhance, considerations of broader material processes that reproduce inequality. Rather than being distinct from wider socio-spatial process that operate on a variety of intersecting spatial scales to reproduce/transform inequalities, social capital should be seen as a constituent component of these mechanisms.

By contrast, Bourdieu's conceptualization of social capital, which is influential within broader social science debates (e.g. see Foley and B.Edwards, 1999; Silva and R.Edwards, 2004), illuminates how sociability can reproduce socio-economic inequalities. However, this version of social capital prioritizes the operations of the political economy and down-plays other embodied differences. The conceptualization of embodied social capital presents geographers with the opportunity to enhance current discussions within the social sciences. Synthesizing performative theorizations of subjectification and social capital illuminates the (re)production of embodied inequalities. Individual identities are not forged in isolation. Rather, subject/agents become relationally. The social norms and expectations reproduced through everyday sociability subconsciously frame identity performances and are, at least partially, incorporated into individuals' subjectivity, with effects on current and future social relationships. These identities can be understood as embodied social capital, as they are the dynamic historical materialization of the interconnections between individuals' social networks and relationships and corporeality. Thus individuals' embodied identities as woman/man, boy/girl, disabled/non-disabled, and in racialized and sexualized terms offer diverse abilities to convert capitals, and position them differently in relation to a host of power relations. 
Crucially, however, these identity locators are not fixed or given. These various norms intersect, and are (re)produced differently, at heterogeneous spatial moments. Gendered identities are classed, sexualized, racialized, (dis)abled, and so on (see for instance C.Allen 2004). The (de)valuations with which different identities are imbued are also socio-spatially shifting. However, individuals embody previous socio-spatial relations as 'habitus' which influences, without determining, future social relations. Importantly, these embodied identity locations reproduce and/or can transform broader axes of privilege and exclusion in a variety of interconnected cultural, social, political arenas; including, crucially, access to economic capitals.

The critical, embodied conceptualization pointed to in this paper presents new methodological challenges for empirically investigating social capital. It is therefore apt to consider some brief points about empirically investigating embodied social capital, although of course, it is not possible to provide a standardized recipe. Empirical evaluation is clearly tied to the conceptualization of the forms and mechanisms of social capital. Crucial here is the need to dismantle an apparent orthodoxy of 'social capital' as exclusively institutionalized social networks and/or socio-cultural values such as levels of trust and reciprocity (ONS, 2002). The alternative vision of social capital presented in this paper suggests the need to explore how individuals become embodied subject/agents within informal (along with formal), everyday (although not necessarily co-present) emotionally painful and gratifying social relationships that make up the gritty lived 'reality' of social life, along with having a critical view to how such relationships variously confer capitals and thus (re)produce or transform broader socio-spatial axes of inequality. 
It would arguably be inappropriate to establish a new orthodoxy of empirical analysis, given critiques levelled at attempts to produce a universally applicable measurement of social capital earlier. Arguably, therefore, embodied social capital can be most effectively mobilized via an eclectic range of methods, underpinned by a reflexive methodology. There are two key and currently somewhat disparate strands of geographic debate that offer insights into the empirical realization of embodied social capital. First, discussions of cultural capital particularly related to gentrification and migration have fore-grounded Bourdieu's concepts of cultural capital and habitus. Second, recent debates about social capital have pointed to the importance of bodily difference in (re)producing capital inequalities. I suggest that dialogue between theorists of social and cultural capital can suggest ways of conceptualizing and empirically operationalizing critical, embodied understandings of social capital. Scholars have drawn upon a variety of methods to examine habitus, cultural capital, and social capital, which could be usefully applied in studies of embodied social capital. Useful strategies have included semi-structured interviews and questionnaires (T.Butler and Robson, 2001; D.Smith and Phillips, 2001; Ley, 2003; Bridge, 2006; Kelly and Lusis, 2006; Walters, 2006), analyses of secondary data sources (Gatrell et al., 2004) and network analyses (Savage et al., 2004).

Empirical mobilization could usefully deconstruct the qualitative/quantitative dichotomy to utilize a variety of methods, either in conjunction within specific projects or via collaboration between researchers across the field (see Holt, 2006 for fuller discussion). For instance, network analysis provide useful insights into the type and extent of individuals' networks (Savage et al., 2004). However, it does little to demonstrate the normative power embedded within such relationships. Given the 
importance placed on beyond conscious elements of embodied practice in the (re)production of embodied social capital, innovative methods could be utilized, that seek to point to limits of representation (see for instance Morton, 2005), along with ethnographies (see McNay, 2004, for an exploration of Bourdieu's phenomenology). Certainly the conceptualization and empirical investigation of social capital should move beyond broad brush analyses of formal civic engagement, which are underpinned by an uncritical notion of the active citizen. Such a view of the active subject can reproduce the marginalization of many individuals, whose citizenship is often already rendered tenuous, including children and young people and those with mind-body-emotional differences.

Arguably, empirically realizing a critical, embodied conceptualization of social capital works at the level of methodology, rather than as a particular set of methods. Critical embodied accounts of social capital can only be understood as context specific and relational to other types of capital. Certainly, critical, embodied accounts of social capital are not ontological explanations, nor can they be universally applied. However, such conceptualizations can provide one tool to encourage attention to the interconnections between the performances and (de)valuations of embodied identities in specific socio-spatial contexts, and the reproduction or transformation of enduring (in)equalities at a variety of intersecting scales.

\section{A VII Conclusion}

In this paper, I have asserted that, despite recent criticisms of social capital, it is a concept that has potential value to enhance geographical analyses of inequality and privilege. Importantly, the notion of social capital can illuminate the differential value 
inherent within social relationships. An alternative conceptualization of embodied social capital is proposed in an endeavour to begin to resignify and challenge dominant representations of social capital. This conceptualization emphasizes how bodies are components of broader socio-spatial relationships, which become differentially imbued with value as they are subjectified along a variety of axes of difference. Thus, embodied social capital facilitates a synthesis of Bourdieu's notion of capital with performative theorizations of identities: serving to reconnect broader embodied differences to wider socio-spatial processes including the political economy, without entirely reducing such differences to the realm of historicalmaterialist relations. Finally, a critical synthesis of Bordieu's capitals and performative theories of identity can suggest possibilities for transformation. The paper provides an impetus to re-open debate and discussion about the usefulness and mobilization of 'social capital' for geographers. Such debates can promote the crossfertilization of conceptualizations of social capital and spatiality between geography and the broader social sciences. 
Forthcoming Progress in Human Geography

\section{References}

Adkins, L. 2004: Introduction: feminism, Bourdieu and after. In Skeggs, B. and Adkins, L. editors, Feminism after Bourdieu, Sociological Review Monograph, Oxford: Blackwell, 3-18.

Aitken, S.C. 2001: Geographies of young people. London/New York: Routledge.

Allen, C. 2004: Bourdieu's habitus, social class and the spatial worlds of visually impaired children. Urban Studies 41, 287-506.

Allen, J. 2003: Lost Geographies of Power. Oxford: Blackwell Publishing.

Amin, A. 2005: Local community on trail. Economy and Society 34, 612-33.

Anderson, K. and Smith, S.J. 2001: Editorial: emotional geographies. Transactions of the Institute of British Geographers 26, 7-10.

Baron, S. 2004: Social capital in British politics and policy making. In Franklin, J., editor, Politics, trust and networks: social capital in critical perspective, London: London South Bank University, 5-16.

Bathelt, H. and Glünckler, J. 2005: Resources in economic geography: from substantive concepts towards a relational perspective. Environment and Planning A $37,1545-1563$.

Bebbington, A. Guggenheim, S. Olson, E. and Woodcock, M. 2004: Exploring social capital debates at the World Bank. The Journal of Development Studies 40, 33-64.

Bell, D. Binnie, J. Cream, J. and Valentine, G. 1994: All hyped up and no place to go. Gender, Place and Culture 1, 31-48

Bourdieu P. 1984: Distinction: a social critique of the judgement of taste. London/New York: Routledge. 
Forthcoming Progress in Human Geography

Bourdieu, P. 1986: The forms of capital. In Richardson, J.G., editor, Handbook of theory and research in the sociology of education, New York: Greenwald Press, 241253.

Bourdieu, P. 1990: The logic of practice. Cambridge: Polity Press. (Translated by Nice, R.).

Bourdieu, P. 2001: Masculine Domination, Stanford: Stanford University Press.

Bourdieu, P. and Passeron, J.C. 1979: The inheritors: French students and their relation to culture. Chicago: University of Chicago Press. (translated by Nice, R.).

Bourdieu, P. and Thompson, J.B. 1991: Language and symbolic power. Cambridge MA: Harvard University Press.

Bourdieu, P. and Wacquant, L. 1992: An invitation to reflexive sociology. Chicago: University of Chicago Press.

Bouveresse, J. 1999: Rules, dispositions and the habitus. In Shusterman, R., editor, Bourdieu: a critical reader, Oxford: Blackwell, 45-63.

Bridge, G. 2001: Bourdieu, rational action and the time-space strategy of gentrification. Transactions of the Institute of British Geographers, 26: 205-216.

Butler, J. 1990: Gender trouble: feminism and the subversion of identity. London/New York: Routledge.

Butler, J. 1993: Bodies that matter: on the discursive limits of 'sex'. London/New York: Routledge.

Butler, J. 1997: The psychic life of power: theories in subjection. Stanford: Stanford University Press.

Butler, J. 1999: Performativity's social magic. In Shusterman, R., editor, Bourdieu: a critical reader, Oxford: Blackwell, 113-29.

Butler, J. 2004: Undoing gender. London/New York: Routledge. 
Butler, R. and Parr, H., editors, 1999: Mind and body spaces: geographies of illness, impairment and disability. London/New York: Routledge.

Butler, T. 1997: Gentrification and the Middle Classes, Aldershot, Hants: Ashgate.

Butler, T. 2002: Thinking Global but Acting Local: the Middle Classes in the City.

Sociological Research Online 7, 3http://www.socresonline.org.uk/7/3/timbutler.html>

Butler, T. and Robson, G. 2001: Social capital, gentrification, and neighbourhood change in London: a comparison of three south London neighbourhoods. Urban Studies 38, $2145-2162$

Butler, T. and Robson, G. 2003b: Plotting the Middle Classes: gentrification and circuits of education in London. Housing Studies 18, 5-28.

Butler, T. with Robson, G. 2003: London Calling, Oxford: Berg.

Coleman, J. S. 1987: Social capital and the development of youth. Momentum 18, 6-8.

Coleman, J. S. 1988: Social capital in the creation of human capital. American Journal of Sociology 94, S95-S120.

Cresswell, T. 1996: In place/out of place: geography, ideology and transgression, Minneapolis: University of Minnesota Press.

Cresswell, T. 2002: Bourdieu's geographies: in memorium. Environment and Planning D: Society and Space 20, 379-382.

Das, R.J. 2004: Social capital and poverty of the wage-labour class: problems with the social capital theory. Transactions of the Institute of British Geographers 29, 27-45.

Davidson, J., Smith, M. and Bondi, L., editors 2005: Emotional geographies. London: Ashgate.

DeFilippis, J. 2001: The myth of social capital in community development. Housing Policy Development 12, 781-806. 
DeFilippis, J. 2002: Symposium on social capital: An introduction. Antipode 34, 790795.

Dewsbury, J.D., Harrison, P., Rose, M. and Wylie, J. 2002: Enacting Geographies introduction. Geoforum 33, 437-40.

Doel M. A. 1995: Bodies without organs: deconstruction and schizoanalysis. In Pile, S. and Thrift, N., editors, Mapping the Subject: Geographies of Cultural Transformation, London: Routledge, 227-41.

Duncan, S.S. and Smith, D.P. 2002: Geographies of partnering and parenting in Britain: spatial differences and gender cultures. Transactions of the Institute of British Geographers 27, 471-93.

Edwards, C. and Imrie, R. 2003: Disability and bodies as bearers of value. SociologyThe Journal of the British Sociological Association 37, 239-56.

Fine, B. 2001: Social capital versus social theory. Political economy and social science at the turn of the millennium. London/New York: Routledge.

Foley, M.W. and Edwards, B. 1999: Is it time to disinvest in social capital? Journal of Public Policy 19, 199-231.

Foucault, M. 1990: The history of sexuality: vol. 1 the will to knowledge. Harmondsworth: Penguin. (translated by R. Hurley).

Gatrell, A.C., Popay, J. and Thomas, C. 2004: Mapping the determinants of health inequalities in social space: can Bourdieu help us? Health and Place 10, 245-57.

Giddens, A. 2000: The Third Way and its critics. Cambridge: Polity Press.

Gregson, N. and Rose, G, 2000: Taking Butler elsewhere: performativities, spatialities and subjectivities. Environment and Planning D: Society and Space 18, 433-52.

Grootaert, C. 1998: Social capital: 'the missing link' in expanding the measure of wealth. SCI Working Paper No. 3, Washington DC: World Bank. 
Grosz, E. 1994: Volatile bodies: toward a corporeal feminism. Indiana: Indiana University Press.

Harrison, P. 2000: Making sense: embodiment and the sensibilities of the everyday. Environment and Planning D: Society and Space 18, 497-517.

Health Development Agency, 2004: Social capital: working with and for communities. HAD Briefing, 21 June.

Holloway, S.L. 1998: Local childcare cultures: moral geographies of mothering and the social organisation of pre-school education. Gender, Place and Culture 5, 29-53. Holt, L. 2003: (Dis)abling children in primary school spaces: geographies of inclusion and exclusion. Health and Place 9, $119-28$.

Holt, L. 2004a: Children with mind-body differences: performing (dis)ability in primary schools classrooms. Children's Geographies 2, 219-36.

Holt, L. 2004b: Childhood disability and ability: (Dis)ableist geographies of mainstream primary schools. Disability Studies Quarterly 24, unpaginated.

Holt, L. 2006: Exploring other childhoods through quantitative secondary analyses of large scale surveys: opportunities and challenges for children's geographers. Children's Geographies 4, 143-55.

Holt, L. forthcoming: Children's socio-spatial (re)production of disability in primary school playgrounds. Environment and Planning D: Society and Space.

Houston, S. Wright. R. Ellis, M. Holloway, S. and Hudson, M. 2005: Places of possibility: where mixed-race partners meet. Progress in Human Geography 29, 700717.

Imrie, R. and Edwards, C. forthcoming: Geographies of disability. Geography

\section{Compass.}


Jackman, R.W. and Miller, R.A. 1996: The poverty of political culture. American Journal of Political Science 40, 697-716.

Jenkins, P. 1992: Pierre Bourdieu, London: Routledge.

Katz, C. 2004: Growing up global: economic restructuring and children's lives. Minneapolis: University of Minnesota Press.

Kelly, P. Lusis, T. 2006: Migration and the transnational habitus: evidence from Canada and the Philippines. Environment and Planning A 38, 831 - 847.

Kitchin, R. 1998: Out of place, knowing one's place: space, power and the exclusion of disabled people. Disability and Society 13, 343-56.

Latham, A. and Conradson, D. 2003: Guest editorial: the possibilities of performance. Environment and Planning A 35 (11), 1901 - 06

Lawler, S. 2004: Rules of engagement: habitus, power and resistance. Sociological Review 52, 110-28.

Ley, D. 2003: Artists, aestheticisation and the field of gentrification Urban Studies 40, $2527-2544$

Li, Y., Savage, M. and Pickles, A. 2003a: Social capital and social exclusion in England and Wales, 1972-1999. British Journal of Sociology 54, 497-526.

Li, Y., Savage, M. and Pickles, A. 2003b: Social change, friendship, and civic participation. Sociological Research Online 8, U412-35.

Li, Y., Savage, M., Tampubolon, G., Warde, A. and Tomlinson, M. 2002: Dynamics of social capital: trends and turnover in associational membership in England and Wales: 1972-1999. Sociological Research Online 7, U97-132.

London/New York: Routledge.

Longhurst, R. 2001: Bodies: exploring fluid boundaries. London/New York: Routledge. 
Forthcoming Progress in Human Geography

Longhurst, R. 2000: Corporgeographies of pregnancy: 'bikini babes'. Environment and Planning D: Society and Space 18, 453-72

Loury, G. 1977: A dynamic theory of radical income differences. In Wallace, P. and Lemund, A., editors, Women, minorities and employment discrimination, Lexington, MA: Heath, 153-86

Martin, R., 2001: Geography and public policy: the case of the missing agenda. Progress in Human Geography 25, 189-210.

Massey D, 2005: For space. London: Sage.

Massey, D. 1994: Space, Place and Gender. Minneapolis: University of Minnesota Press.

McNay, L. 2000: Gender and agency: reconfiguring the subject in feminist and social theory. Cambridge: Polity Press.

McNay, L. 2004: Agency and experience: gender as a lived relation. Sociological Review 52, 175-90.

Mohan, G. and Mohan, J. 2002: Placing social capital. Progress in Human Geography 26, 191-210.

Mohan, J., Twigg, L., Barnarda, S. and Jones, K. 2005: Social capital, geography and health: a small-area analysis for England. Social Science and Medicine 60, 1267-83. Morrow, V. 1999: Conceptualising social capital in relation to the well-being of children and young people: a critical review. Sociological Review 47, 744-66.

Morrow, V. 2001: Young people's explanation and experiences of social exclusion: retrieving Bourdieu's concept of social capital. International Journal of Sociology and Social Policy 21, 37-63.

Morton, F. 2005: Performing ethnography: Irish traditional music sessions and new methodological spaces. Social \& Cultural Geography 6, 661-676. 
Moss, P. and Dyck, I. 1996: Inquiry into environment and body: women, work and chronic illness. Environment and Planning D: Society and Space 14,737 - 77.

Nash, C. 2000: Performativity in practice: some recent work in cultural geography. Progress in Human Geography 24, 653-64.

Nash, R. 2003: Inequality/difference in New Zealand education: social reproduction and the cognitive habitus. International Studies in Sociology of Education 13, 73-191. Nederveen Pieterse, J. 2006: Social capital and migration - beyond ethnic economies. In Radcliffe, S.A. (ed.) Culture and Development in a Globalising World, London/New York: Routledge, 126-149.

ONS, 2002: Social Capital Matrix of Surveys. London: Office for National Statistics. Painter, J. 2001: Pierre Bourdieu. In Crang, M. and Thrift, N., editors, Thinking space, London/New York: Routledge, 239-59.

Podmore, J. 1998: (Re)reading the 'Loft Living' habitus in Montreal's inner city. International Journal of Urban \& Regional Research 22, 283 - 302.

Ponthieux, S. 2004: The concept of social capital: a critical review. Paper presented at 10th CAN conference, Paris, 21-23 January.

Portes, A. and Landolt, P. 1996: Unsolved mysteries: the Tocqueville files II. The American Prospect 7, 18-21

Portes, A., 1998: Social capital: its origins and applications in modern sociology. Annual Review of Sociology 24, 1-15.

Probyn E. 2004: Shame in the habitus. The Sociological Review 52, 224-248.

Putnam, R. 2000: Bowling alone, the collapse and revival of American community. New York: Simon and Schust.

Putnam, R.D. Leonardi, R. and Nanettis, R. 1993: Making democracy work: civic traditions in modern Italy. Princeton, NY: Princeton University Press. 
Radcliffe, S.A. 2004: Geography of development I: development, civil society and inequality-social capital is (almost) dead? Progress in Human Geography 28, 517-27. Radcliffe, S.A. 2005a: Neoliberalism as we know it, but not in conditions of its own choosing: a commentary. Environment and Planning A 37, 323-39,

Radcliffe, S.A. 2005b: Development and geography II: towards a postcolonial development geography? Progress in Human Geography 29, 291-298.

Radcliffe, S.A., 2006: Culture in development thinking: geographies, actors and paradigms. In Radcliffe, S.A. (ed.) Culture and Development in a Globalising World. Reay, D. 2004: Gendering Boudieu's concept of capitals? Emotional capital, women and social class. Sociological Review 52, 57-74.

Reay, D. 2004b: 'It's all becoming a habitus': beyond the habitual use of habitus in educational research. British Journal of Sociology of Education 25, 421-444.

Rose, G. 1993: Feminism and geography: the limits of geographical knowledge. Minneapolis: Univ. of Minnesota Press.

Rose, G. 1997: Situating knowledges: positionality, reflexivities and other tactics. Progress in Human Geography 21, 305-20.

Rose, M. 2002: The seductions of resistance: power, politics and a performative style of systems. Environment and Planning D: Society and Space 20, 383-400.

Savage, M., Tampubolon, G. Warde, A. 2004: Social capital and political activism: a social network approach. In Franklin, J., editor, Politics, trust and networks: social capital in critical perspective, London: South Bank University, 23-37.

Schaefer-McDaniel, N.J. 2004: Conceptualizing social capital among young people: toward a new theory. Children, Youth and Environments 14, 153-72.

Shilling, C. 1997: Emotions, embodiment and the sensation of society. Sociological Review 45, 195-217. 
Shilling, C. 2003: The body and social theory. London: Sage.

Silva, E.B. and Edwards, R. 2004: Operationalizing Bourdieu on capitals: a discussion on 'the construction of the object'. ESRC Research Methods Programme, Working Paper No 7.

Silva, E.B., 2005: Gender, home and family in cultural capital theory. British Journal of Sociology 56, 83-103

Silvey, R, and Elmhurst, R., 2003: Engendering social capital: women workers and rural-urban networks in Indonesia's crisis. World Development 31, 865-79.

Smith, D.P. and Phillips, D. 2001: Socio-cultural representations of greentrified Pennine rurality. Journal of Rural Studies 17, 457-69.

Social Exclusion Unit, 2004: Breaking the cycle: taking stock of progress and priorities for the future. Office of the Deputy Prime Minister, September.

Thomas, M.E. 2005, 'I think it's just natural': the spatiality of racial segregation at a US high school. Environment and Planning A 37, 1233-48.

Thomas, W. and Webber, D. J. 2001: 'Because my friends are': the impact of peer groups on intention to stay on at sixteen. Research in Post-Compulsory Education 6, 339-54.

Thrift, N. 2004: Intensities of feeling: towards a spatial politics of Affect. Geografiska Annalar 86B, 57-8.

Thrift, N., Dewsbury J.D., 2000: Dead geographies and how to make them live. Environment and Planning D: Society and Space 18, 411-32.

Turner, S. and An Nguyen, P. 2005: Young entrepreneurs, social capital and Doi Moi in Hanoi, Vietnam. Urban Studies 42, 1693-1710.

Valentine, G. 2005: Geography and ethics: moral geographies? Ethical commitment in research and teaching. Progress in Human Geography 29, 483-87. 
Valentine, G. and Skelton, T. 2003: Living on the edge: The marginalisation and resistance of D/deaf Youth. Environment and Planning A 35, 301-321.

Walters, J. 2006: Geographies of cultural capital: education, international migration and family strategies between Hong Kong and Canada. Transactions of the Institute of British Geographers 31, 179-192.

Zukin S, 1995 The Cultures of Cities, Oxford, Blackwell.

\section{Acknowledgements}

I would like to thank all the young people and adults that took part in the research that inspired this paper, and the EPRSC Geographical Grant that funded this research. Thanks also go to two anonymous referees and the editor for their constructive comments.

\footnotetext{
i 'The Third Way' is often attributed to Anthony Giddens. It has been adopted as political approach which claims to chart a broadly social democratic path between 'statist democracy' and neoliberalism (see Giddens, 2000 for a positive review).
}

${ }^{\text {ii }}$ Despite the title of Foley and B.Edwards (1999), they conclude that the concept of social capital has analytic value, and should not be entirely jettisoned (cf. Fine, 2001).

iii Notwithstanding this general disinvestment, social capital continues to feature prominently within certain inter-disciplinary fields, such as the examination of health inequalities, particularly in seeking to explain neighbourhood effects (see Mohan and Mohan, 2002); economic geography (Bathelt and Glückler, 2005); and geographies of development (Radcliffe, 2006).

${ }^{\text {iv }}$ Coleman $(1987,1988)$ has also been influential, particularly in relation to education, and as an inspiration to Putnam (see Schaefer-McDaniel, 2004).

${ }^{\mathrm{v}}$ Neo-liberalism is associated with moves towards increasing freedom of the market economy, reduction in universal welfare states, and state protection (except for those associated with the rights of the individual and the market), increasingly targeted welfare systems, and often, increasing reliance on non-state civic organisations. Radcliffe (2005a) emphasizes the complex spatial variations in the ways in which general neo-liberal shifts are interpreted within various national and sub-national contexts, suggesting that neo-liberalism is most usefully understood as generalized trends and tendencies diversely played out rather, than a homogeneous enterprise.

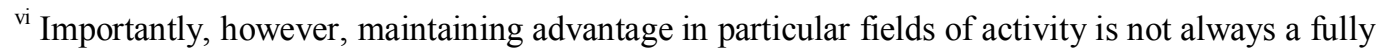
conscious and rational act.

vii ' a field ... [is] a network, or a configuration, of objective relations between positions objectively defined, in their existence and in the determinations they impose upon their occupants, agents or institutions, by their present and potential situation ... in the structure of and distribution of power (or 
capital) whose possession commands access to the specific profits that are at stake in the field, as well as by their objective relation to other positions...' (Bourdieu and Wacquant, 1992: 39)

${ }^{\text {viii }}$ Some commentators have contended that Butler does not provide an account of agency and removes from individuals the capacity to act (McNay, 2000). Although McNay arguably underplays the role of material bodies and non-discursive action in Butler's performativity, I would concede that Butler often deconstructs liberal, Modern conceptualizations, rather than providing a fully workable alternative, agency. Butler's later work (especially Butler, 2004) redresses this balance somewhat, although it seems to return, to a degree, to an autonomous liberal notion of agency.

ix Debates about the 'relevance' of human geography often underplay both the potential for examining enduring inequalities inherent within much post-structuralist discussions, and substantive examinations of such material considerations in a great deal of feminist and post-colonialist thought (see for instance Radcliffe, 2005b).

x This adds another layer onto Portes' (1998) critique of the restricted individual freedom often associated with strong community networks and shared normative values. 